\title{
Responsabilidade social, sustentabilidade e inovação no setor sucroenergético brasileiro: Tendências e perspectivas
}

Social responsibility, sustainability and innovation in the Brazilian sugar-energy sector: Trends and perspectives

Responsabilidad social, sustentabilidad e innovación en el sector azucarero-energético brasileño:

Tendencias y perspectivas

Recebido: 25/03/2021 | Revisado: 31/03/2021 | Aceito: 01/04/2021 | Publicado: 12/04/2021

Téucle Mannarelli Filho

ORCID: https://orcid.org/0000-0003-0040-0517 Universidade Estadual Paulista "Júlio de Mesquita Filho", Brasil

E-mail: teucle@terra.com.br

Frederico Andreis Beneli Donadon

ORCID: https://orcid.org/0000-0002-4146-2231 Universidade Estadual Paulista "Júlio de Mesquita Filho", Brasil E-mail: fredericodonadon @usp.br

Giuliana Aparecida Santini Pigatto

ORCID: https://orcid.org/0000-0001-9737-6036 Universidade Estadual Paulista "Júlio de Mesquita Filho", Brasil E-mail: giuliana.santini@unesp.br

Timóteo Ramos Queiróz

ORCID: https://orcid.org/0000-0001-9327-4462 Universidade Estadual Paulista "Júlio de Mesquita Filho", Brasil E-mail: timoteo.queiroz@unesp.br

Renato Dias Baptista

ORCID: https://orcid.org/0000-0003-2270-1230 Universidade Estadual Paulista "Júlio de Mesquita Filho", Brasil E-mail: rd.bapstista@unesp.br

\begin{abstract}
Resumo
É inegável o espaço que a Responsabilidade Social e demais temáticas correlacionadas como, Sustentabilidade e Inovação têm conquistado nas discussões acadêmicas e na sociedade em geral, face principalmente a mudanças globais de ordem econômica, social, política e ambiental, cujas atividades e ações positivas contribuem sobremaneira para a ampliação do bem-estar social e/ou das organizações. Neste contexto emergiu o objetivo deste estudo de apresentar um panorama sobre tendências e perspectivas do setor sucroenergético para a próxima década, tendo como escopo a Análise de Conteúdo (AC), no caso, voltada à revisão da literatura sobre temas como Responsabilidade Social, Responsabilidade Socioambiental, Sustentabilidade, Inovação Tecnológica e outros, envolvidos no setor de produção de açúcar e álcool no país. Metodologicamente conduziu-se uma pesquisa com abordagem qualitativa, tratada e validada pelo IRAMUTEQ, via Análise de Similitude e frequência de palavras. Os resultados obtidos demonstram que o objetivo foi alcançado, tanto por meio da revisão bibliográfica e documental, que possibilitou caracterizar as variáveis da pesquisa pelo diferencial do uso de modelos teóricos que se mostraram adequados à realidade e que poderão ser explorados em outros estudos.
\end{abstract}

Palavras-chave: Brasil; Setor sucroenergético; Responsabilidade social; Inovação.

\begin{abstract}
It is undeniable the space that Social Responsibility and other related topics such as Sustainability and Innovation have conquered in academic discussions and in society in general, especially in the face of global economic, social, political and environmental changes, whose positive activities and actions contribute greatly to the expansion of social well-being and / or organizations. In this context, the objective of this study emerged to present an overview of, trends and perspectives of the sugar-energy sector for the next decade, having as scope the Content Analysis (AC), in this case, focused on the literature review on topics such as Social Responsibility, Social and Environmental Responsibility, Sustainability, Technological Innovation and others, involved in the sugar and alcohol production sector in the country. Methodologically, a research with a qualitative approach was conducted, treated and validated by IRAMUTEQ, via Similitude Analysis and word frequency. The results obtained demonstrate that the objective was achieved, both through the bibliographic and documentary review, which made it possible to characterize the research variables by differentiating the use of theoretical models that proved to be adequate to reality and that could be explored in other studies.
\end{abstract}


Keywords: Brazil; Sugar-energy sector; Social responsability; Innovation.

\section{Resumen}

Es innegable el espacio que la Responsabilidad Social y otros temas afines como la Sustentabilidad y la Innovación han conquistado en las discusiones académicas y en la sociedad en general, especialmente ante los cambios económicos, sociales, políticos y ambientales globales, cuyas actividades y acciones positivas contribuyen en gran medida a la expansión del bienestar social y / o de las organizaciones. En este contexto, el objetivo de este estudio surgió de presentar un panorama, tendencias y perspectivas del sector azucarero-energético para la próxima década, teniendo como alcance el Análisis de Contenido (CA), en este caso, enfocado en la revisión de la literatura sobre temas como Responsabilidad Social, Responsabilidad Social y Ambiental, Sustentabilidad, Innovación Tecnológica y otros, involucrados en el sector de producción de azúcar y alcohol en el país. Metodológicamente, se realizó una investigación con enfoque cualitativo, tratada y validada por IRAMUTEQ, vía Análisis de Similitud y frecuencia de palabras. Los resultados obtenidos demuestran que se logró el objetivo, tanto a través de la revisión bibliográfica como documental, que permitió caracterizar las variables de investigación por el diferencial del uso de modelos teóricos que resultaron adecuados a la realidad y que pueden ser explorados en otros estudios.

Palabras clave: Brasil; Sector de energía azucarera; Responsabilidad social; Innovación.

\section{Introdução}

É inegável o espaço que a Responsabilidade Social e as demais temáticas correlacionadas, como Sustentabilidade e Inovação, têm conquistado nas discussões acadêmicas e na sociedade em geral, face principalmente a mudanças globais de ordem econômica, social, política e ambiental, cujas atividades e ações positivas contribuem sobremaneira para a ampliação do bem-estar social e/ou das organizações.

Nesse contexto, Aligleri \& Borinelli (2001) ratificam a concepção atual de Responsabilidade Social como a "atuação legítima e voluntária das empresas com a comunidade externa e interna na qual elas estão inseridas". Fellenberg (1980) registra que o envolvimento voltado à Responsabilidade Social não é recente, já que a preocupação em empreender ações coordenadas com características de Responsabilidade Social pode ser observada desde o século XIV. Segundo o autor, no passado as bases teóricas para suportar tais ações eram restritas, porém já representavam comportamentos voltados para o bem da sociedade.

No caso da Responsabilidade Socioambiental, Melo Neto \& Froes (2001) observam que, notadamente no início da década de 1990, o movimento voltado a essa corrente ganhou forte impulso e organização, principalmente em decorrência dos resultados da Primeira e Segunda Conferências Mundiais da Indústria sobre gerenciamento ambiental, ocorridas respectivamente em 1984 e 1991.

Nos anos posteriores surgem movimentos em prol de mudanças sociais, científicas e tecnológicas, quando as organizações empreendem novas posturas em relação ao meio ambiente, ancoradas em estratégias práticas, fundamentadas em parâmetros como bom relacionamento com a comunidade e com os organismos ambientais, estabelecimento de uma política de gestão ambiental, uso de tecnologia limpa e definição de um compromisso ambiental com vistas ao desenvolvimento sustentável, entre outras (Andion, Alperstedt \& Graeff, 2020).

Quanto à Responsabilidade Social Corporativa (RSC), esta vem sendo discutida no meio acadêmico desde a década de 50 em situação que culminou no surgimento de normas e padrões de certificação social e ambiental, dentre elas a AS 8000, AA1000 e ISO 14000. Mendonça \& Gonçalves, (2004) ratificam a concepção de Schommer \& Fischer (1999) de que a ideia de responsabilidade social nos negócios ganhou impulso no Brasil, especialmente, a partir da criação do Instituto Ethos de Empresas e Responsabilidade Social, em setembro de 1998 (Cruz, 2015).

Hoje a busca pela legitimidade no desenvolvimento de ações de cunho social passou a fazer parte do cotidiano de muitas empresas brasileiras, que reconhecem ou acreditam que tais ações têm impactos positivos em sua imagem corporativa, inclusive sob a crença de que a sociedade atribui a elas um valor que vai além do comportamento ético e legal (Oliveira \& Gouvea, 2010). 
Em acréscimo ao contexto exposto, debates e reflexões sobre a necessidade emergente de preservação do meio ambiente levam ao conceito sistêmico de Sustentabilidade, voltado a aspectos econômicos, políticos, sociais, culturais e ambientais, dentre outros. Assim, na ausência ou desigualdade na atuação dos agentes comprometidos com o desenvolvimento sustentável tem-se o desequilíbrio, que pode suscitar a necessidade de medidas corretivas no curto, médio e longo prazo, com desgastes e dispêndios financeiros, conforme a intensidade, tempo e abrangência dos fatores envolvidos com a sociedade humana (Domeneghetti \& Meir, 2009).

Nesse cenário, uma visão futura demanda esforços que possam culminar em trajetória positiva de aprendizado, se levarmos em conta o conceito de Inovação proposto por Schumpeter. De acordo com Furtado, Scandiffio, \& Cortez (2010), a evolução do conceito de inovação vinculada à geração de valor econômico levou Schumpeter a reconhecer posteriormente que as organizações poderiam, sim, viabilizar diferentes formatos de inovação, ancorados em atividades científicas e tecnológicas; (Schumpeter, 1985; Bignetti, 2011; Pelegrin \& Antunes Jr, 2013.).

Assim, a criação de práticas sustentáveis com vistas à adaptação ou mesmo diferenciação frente aos concorrentes, cria a necessidade de produtos com fortes conceitos e propostas, concebidos e construídos com critérios relacionados à sustentabilidade, em situação que configura a necessidade de conexão entre Responsabilidade Social e Inovação (Andrade, 2017).

Dos excertos aqui expostos, pesquisados a partir de temáticas como Responsabilidade Social, Responsabilidade Socioambiental, Sustentabilidade e Inovação, alçadas à categoria de "pilares da cidadania no século XXI" por Clock, Heidemann, Moraes, \& Baldin (2015), denota-se uma percepção mundial quanto ao atual modelo de desenvolvimento no sentido de que seja repensado e reconstruído constantemente, de forma a privilegiar não apenas a necessidade individualista do cidadão, mas sim o coletivo, a preocupação com o todo.

Repensada a metodologia inicial com vistas à redução do universo pesquisado, decidiu-se por um único setor de evidência no momento atual do país. A opção recaiu sobre o Agronegócio brasileiro por motivos diversos, dentre eles, a identificação e familiaridade com a área, pelo Agro ser um sistema que contribui sobremaneira para o desenvolvimento do país, geração de empregos, renda e divisas e, finalmente, por fazer parte dos estudos atuais empreendidos (viabilizados por meio de uma visão interdisciplinar via diálogo de saberes, em processo que aproxima os aprendizados específicos procedentes da Economia, Gestão, Ciências Animal e Vegetal, Meio Ambiente, Sociologia, Comunicação, Tecnologia e Inovação).

No contexto do Agronegócio, optou-se, mais especificamente pela cadeia produtiva da cana-de-açúcar, um segmento de atividade que ao longo de mais de 500 anos de história nacional tem sido parte da estrutura econômica, política e social do país e que, na atualidade, tem procurado aperfeiçoar seu setor sucroenergético de forma contínua, principalmente no tocante à Responsabilidade Socioambiental e Inovação Tecnológica (Carvalho, 2012).

Neste contexto emergiu o objetivo deste estudo de apresentar um panorama do setor sucroenergético nas duas últimas décadas e potenciais tendências e perspectivas para a próxima década, utilizando-se de uma revisão bibliográfica, seleção de artigos aderentes ao objetivo e utilização de um software de análise de palavras contidas nos artigos pré-selecionados.

Este artigo está organizado em cinco seções, incluindo esta introdutória. A seção dois apresenta a metodologia utilizada na pesquisa, na seção três se apresenta além da caracterização da agroindústria canavieira no Brasil, a revisão da literatura sobre a pluralidade de conceitos e temas atuais correlacionados com o setor sucroalcooleiro, como Responsabilidade Social, Responsabilidade Socioambiental, Sustentabilidade e Inovação Tecnológica. Na seção quatro são apresentados os resultados do estudo e a análise em relação ao mapeamento da produção científica tratada e validado pelo IRAMUTEQ. A seção cinco registra as considerações finais. 


\section{Metodologia}

A metodologia adotada neste estudo está pautada na abordagem qualitativa de Oliveira \& Gouvea, (2010) e registra que a pesquisa qualitativa visa facilitar a apresentação do tema pesquisado, sendo utilizada para discutir em profundidade, as características e o significado do contexto, em que o mesmo se encontra inserido. Para Godoy, (1995) referida modalidade de pesquisa é comumente utilizada na obtenção de dados e/ou evidências que confirmem ou neguem suposições preliminares.

Silva, Gobbi, \& Simão, (2005) observam, entretanto, que a pesquisa qualitativa não apresenta um esquema rígido de utilização. Cabe, assim, ao pesquisador, segundo as autoras, utilizar a flexibilidade, a partir do compromisso de apresentar um quadro de nitidez teórica e de postura metodológica que pede um processo contínuo de validação.

Quanto aos objetivos, a pesquisa em referência tem caráter exploratório, por proporcionar maior familiaridade com o problema, inclusive explicitá-lo, se necessário, no caso de restritas informações sobre o objeto alvo da pesquisa (Gil, 2008; Dalfovo, Lana \& Silveira, 2008).

Em relação aos procedimentos técnicos o estudo assume a forma de pesquisa bibliográfica e documental, na busca pela seleção, organização e interpretação das informações obtidas, com a finalidade de se discutir e refletir sobre determinado fenômeno de interesse, ou identificar como determinado tema tem sido tratado dentro de um contexto específico.

Segundo Kripka, Scheller, \& Bonotto (2015), apesar de guardarem semelhanças entre si, as pesquisas documentais diferem-se das bibliográficas quanto à composição de materiais, já que na pesquisa documental a fonte consultada, via de regra, ainda não recebeu tratamento analítico, ou seja, o documento não foi ainda analisado e sistematizado, o que requer uma pesquisa mais cuidadosa.

Quanto aos meios, fez-se uso da Análise de Conteúdo (detalhada à frente, na subseção 3.1) como ferramenta para a pesquisa de análise documental, ancorada em artigos científicos, relatórios e reportagens publicadas em sites eletrônicos, dentre outros, das principais organizações que tratam da temática envolvida. Quanto aos fins, a presente pesquisa enquadra-se como descritiva, por propor, sem que haja a interferência do pesquisador, a análise dos dados coletados e a descrição de experiências, processos, situações e fenômenos, dentre outros (Gil, 2008).

Para tratamento e validação dos dados compilados utilizou-se o Software $R$ (www.r-project.org), desenvolvido pelo pesquisador francês Pierre Ratinaud em 2009, bem como a linguagem Python (www.python.org), onde se ancora o software de análise textual IRAMUTEQ (Interface de R pour les Analyses Multidimensionnelles de Textes et de Questionnaires), com resultados obtidos a partir da Análise de Similitudes ou Semelhanças e por Nuvem de Palavras (Ratinaud, 2009).

Como o IRAMUTEQ é um método informatizado para análise de textos que busca apreender a estrutura e a organização dos discursos através das relações entre os mundos lexicais mais frequentes enunciados nos contextos, o estudo procurou lançar mão na literatura clássica dos temas pesquisados e das publicações disponíveis nos portais de periódicos científicos como CAPES Scopus, Google Acadêmico e Web of Science, bem como nos sites de órgãos governamentais e institucionais envolvidos.

A busca das publicações nos sites envolveu palavras chaves temáticas: setor alcooleiro, agroindústria canavieira, responsabilidade socioambiental, indicadores de mensuração de ações de responsabilidade social, responsabilidade social empresarial, responsabilidade social corporativa, comunicação empresarial, inovação, inovação tecnológica, inovação social, setor agroenergético; e que estão descritas na Figura 1, sendo selecionados 50 artigos, que tinham aderência com o objetivo deste artigo, e aplicados no software IRAMUTEC

Buscou-se, assim, identificar o conhecimento científico possível produzido no período delimitado (duas primeiras décadas do século atual) sobre o tema principal do estudo (setor sucroenergético), nas bases de dados pesquisadas, de forma a constituir o corpus textual, posteriormente tratado e validado pelo IRAMUTEQ. 


\subsection{Detalhamento da Análise de Conteúdo (AC) proposta}

Os dados da presente pesquisa qualitativa estão embasados nos referenciais teóricos para Análise de Conteúdo (AC) propostos por Bardin (2011), Godoy (1995), Silva, Gobbi, \& Simao (2005).

Bardin, (2011) conceitua a AC como um conjunto de técnicas (métodos) de análise das comunicações, que utiliza procedimentos sistemáticos e objetivos de descrição do conteúdo das mensagens, com a intenção de inferir conhecimentos. Segundo a autora, na AC o que deve servir de informação e embasamento é a presença/ausência de uma dada característica de conteúdo ou de um conjunto de características que deve ser levado em consideração.

Godoy, (1995) destaca a utilização da AC em três fases fundamentais, sugeridas por Bardin (2011): a pré-análise e exploração do material na primeira fase, quando é estabelecido um esquema de trabalho que deve ser preciso, com procedimentos bem definidos, embora flexíveis. A segunda fase consiste no cumprimento das decisões tomadas anteriormente, e finalmente na terceira etapa, o pesquisador apoiado nos resultados brutos procura torná-los significativos e válidos (Silva, Gobbi, \& Simao, 2005).

Para viabilização da $1^{\text {a }}$ fase da AC elegeram-se as palavras-chaves (temáticas expostas na Figura 1 subsequente), baseando-se nos objetivos deste estudo, e norteados pela revisão sistemática da literatura, empreendida com base nos procedimentos metodológicos da Análise de Conteúdo. Todas essas palavras-chaves foram utilizadas inicialmente para a seleção dos trabalhos e, posteriormente, como fonte para a compilação do conteúdo utilizado para compor o corpus textual, a ser tratado e validado pelo IRAMUTEQ.

Figura 1. Temáticas selecionadas para revisão da literatura.

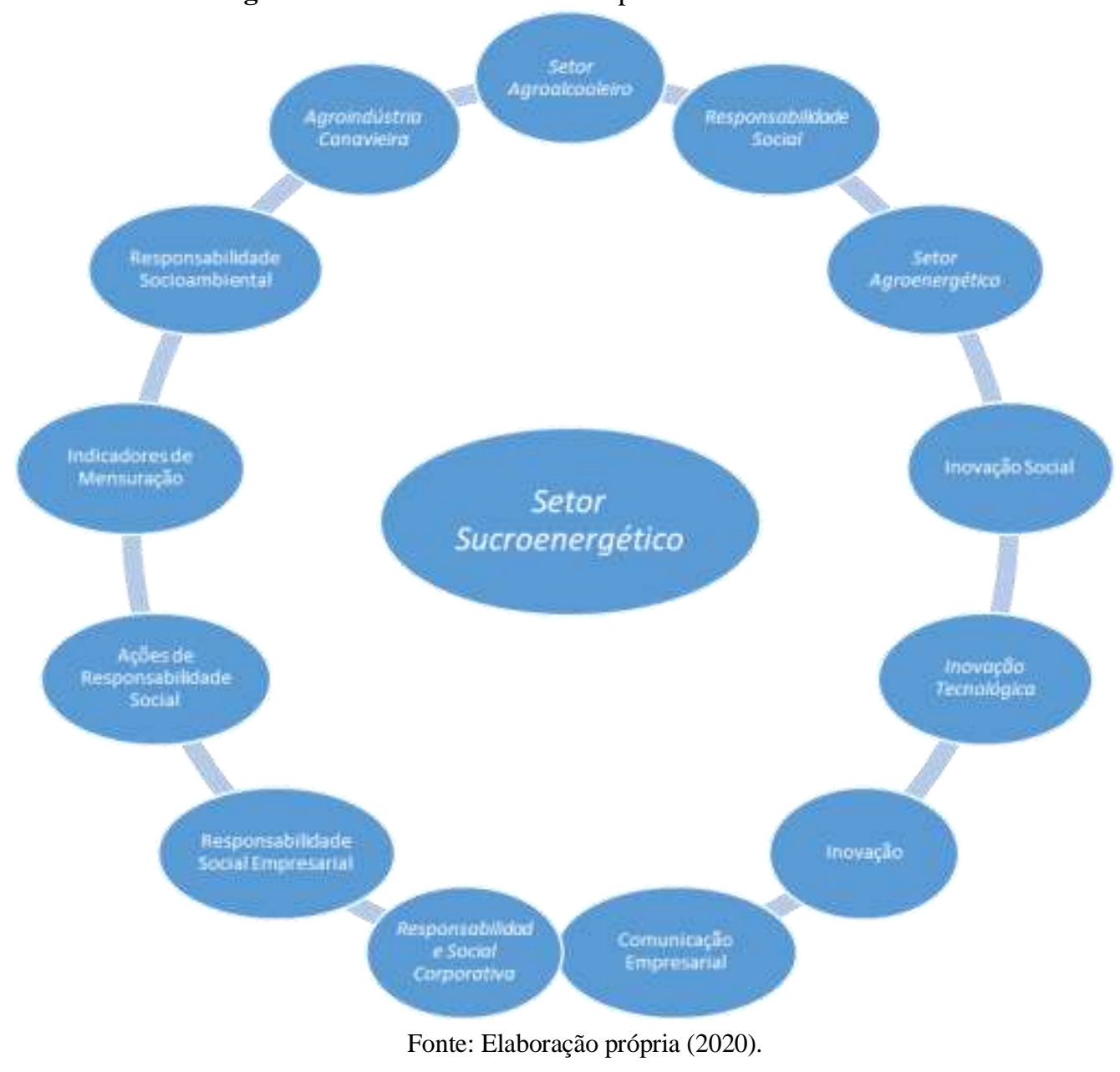




\subsection{Software utilizado no Tratamento e Validação dos Dados Compilados na AC}

Para o tratamento e validação dos dados compilados utilizou-se o Software $R$ (www.r-project.org), desenvolvido pelo pesquisador francês Pierre Ratinaud em 2009, bem como a linguagem Python (www.python.org), onde se ancora o software de análise textual IRAMUTEQ (Interface de R pour les Analyses Multidimensionnelles de Textes et de Questionnaires), com resultados obtidos a partir da Análise de Similitudes ou Semelhanças e por Nuvem de Palavras.

A Tabela 1, na sequência, traz a estrutura das ferramentas utilizadas para coleta, análise, exploração, tratamento e validação dos dados obtidos.

Tabela 1 Síntese das Dimensões do Software de Tratamento e Validação dos Dados.

\begin{tabular}{l|l}
\hline Ferramenta & $\begin{array}{l}\text { Software de Análise Textual } \\
\text { IRAMUTEQ }\end{array}$ \\
\hline Referêncial Teórico de Apoio & $\begin{array}{l}\text { Interface de R pour les Analyses } \\
\text { Multidimensionnelles de Textes et de } \\
\text { Questionnaires (Ratinaud, 2009). }\end{array}$ \\
\hline Objetivo & $\begin{array}{l}\text { Tratamento e Validação dos dados } \\
\text { obtidos. }\end{array}$ \\
\hline Dimensões Analisadas & -Análise de Similitude \\
\hline
\end{tabular}

Fonte: Elaboração própria (2020).

\section{Revisão da literatura}

\subsection{Pluralidade de Nomenclaturas correlacionadas à Agroindústria Canavieira}

Ao longo do estudo em pauta mereceu atenção a pluralidade de nomes e designações usados no âmbito do Agronegócio brasileiro para tratar dos assuntos correlacionados à cana-de-açúcar, dentre eles, o mais tradicional e comum, Setor Canavieiro, substituído por Setor Sucroalcooleiro e mais recentemente por Setor Sucroenergético que, segundo Carvalho, (2012), tem sido utilizado pelas empresas para se referir às atividades que envolvem a indústria canavieira por dar um viés de modernidade e fazer referência à geração de energia elétrica pelas usinas e ao etanol como combustível.

Designações outras como Agroindústria Canavieira, Setor Energético da Cana, Agroindústria do Etanol, Sistema Sucroenergético, Indústria Sucroalcooleira, dentre outras, foram também encontradas, porém com menor frequência nos trabalhos mais recentes.

Depreende-se do contexto pesquisado que a ocorrência da pluralidade de termos se deve à magnitude do setor, bem como à grande variedade e usos alternativos da cana-de-açúcar, dentre eles a fabricação do açúcar, um alimento básico do homem, além de outros numerosos derivados e subprodutos, todos de grande utilidade como o álcool, o melaço, a aguardente, fermento para panificação, celulose, proteína para rações, fertilizantes, dentre outros (Carvalho, 2012).

Como formato reducionista do universo dessas variantes das nomenclaturas, na redação do presente estudo, foram mais usualmente utilizadas as expressões "Agroindústria Canavieira" e "Setor Sucroenergético" para os registros diversos, porém, quando da Análise de Conteúdo, todas as designações temáticas, expressões e vocábulos selecionados foram considerados para compor o corpus textual do IRAMUTEQ. 


\subsection{Caracterização no país da Agroindústria Canavieira e Setor Sucroenergético}

O desenvolvimento da indústria canavieira no Brasil vem desde o período colonial. Essa trajetória longeva é assim ratificada por (Carvalho, 2012):

A cana-de-açúcar, portanto, tem uma longa história no território pátrio. Da colônia ao Império, passando pela Primeira República e o Estado Novo, vivenciando a ditadura e a redemocratização, a cana sempre esteve presente na história mercadológica, política e social do país, influenciando, para além da economia, os costumes e a própria sociedade onde se desenvolveu e ainda se perpetua (Carvalho, 2012, p. 64-65).

Shikida, Azevedo, \& Vian, (2011) relatam que a partir da década de 1950 a região centro-sul, especialmente São Paulo, passa a se destacar na produção canavieira do Brasil e a concentrar grande parte da capacidade de processamento do país, via produção de açúcar e etanol (Camara \& Caldarelli, 2016).

Na concepção de Moraes \& Zilberman (2014), o processo de consolidação do setor sucroenergético no país passou inicialmente, pela rígida intervenção estatal nos processos de planejamento e gestão desse mercado através da implantação do Programa Nacional do Álcool (Proálcool) em 1975, em situação que contribuiu sobremaneira para a expansão e consolidação do mercado brasileiro de biocombustíveis frente à crescente demanda mundial por fontes renováveis e alternativas de energia e, num segundo momento decisivo, em 1999, pela desregulamentação do setor, que passa a operar sem subsídios estatais (Silva, 2015; Camara \& Caldarelli, 2016).

Segundo Sampaio (2015), dois acontecimentos recentes transformaram radicalmente o setor sucroenergético no Brasil. O primeiro, de natureza regulatória, foi a extinção do Instituto do Açúcar e do Álcool (IAA) em 1991, decisão política de cunho neoliberal que afastou o Estado do controle direto do setor. O segundo, de natureza tecnológica, foi a produção de veículos equipados com motores capazes de rodar com gasolina e etanol em quaisquer proporções, conhecidos como flexfuel, a partir de 2003. Segundo os autores, esses dois eventos, articulados a outros de caráter mais amplo, levaram a uma reestruturação, expansão territorial, internacionalização e oligopolização do setor no país, consolidando a chamada macrorregião canavieira do Centro-Sul do Brasil.

Assim, a partir da década de 2000, a expansão canavieira se difundiu rapidamente em porções selecionadas do território brasileiro estimulada pela alta na demanda interna do etanol hidratado para motores dado o crescimento da frota de veículos flexfuel e na demanda externa (etanol anidro para misturar à gasolina em diversos países) em função do Protocolo de Kyoto e da busca por alternativas renováveis de energia, além da elevação dos preços internacionais do açúcar (Castillo, 2016).

$\mathrm{Na}$ atualidade a agroindústria canavieira tem sido considerada de grande importância enquanto atividade estratégica na economia brasileira, tanto por estar inserida em um sistema consolidado, potencializado pela força principalmente da produção de açúcar (para segurança alimentar e para exportação), da energia sustentável (produção de etanol utilizado como combustível automotivo renovável) e da energia elétrica por cogeração, dentre outros, como por exercer um papel expressivo na absorção de mão de obra e como fonte de arrecadação de tributos em toda sua cadeia produtiva (Shikida \& Souza, 2009; Wissmann, Shikida, \& Ayala, 2018).

Não obstante a importância do setor sucroenergético, denota-se pelos referenciais pesquisados que o mesmo tem causado impactos econômicos e socioambientais negativos que ocorrem, tanto nas etapas agrícola e industrial da produção de açúcar e álcool, como no tocante à Responsabilidade Social, uma vez que fatores como a concentração fundiária pela monocultura extensiva, sazonalidade na demanda de mão de obra e o potencial de riscos ambientais suscitam fortes pressões. Sobretudo a partir da promulgação da Política Nacional de Meio Ambiente (1981), o setor empresarial tem procurado se adequar cada vez mais às exigências legais e a novos padrões de mercado (Wissmann \& Shikida, 2017).

Hoje a abrangência geográfica do setor sucroenergético se estende a diversas regiões do Brasil, notadamente no Nordeste e Centro Sul. Só o Estado de São Paulo concentra aproximadamente 180 agroindústrias representativas de cerca de 
$60 \%$ da produção de cana-de-açúcar no país UNICA, (2020). Segundo dados da Companhia Nacional de Abastecimento CONAB, (2020), o país alcançou a produção recorde de 35,6 bilhões de litros de biocombustível da cana-de-açúcar e do milho na safra 2019/2020, 7,5\% a mais sobre a safra 2018/2019.

De acordo com a análise técnica de levantamento referente à safra 2019/2020, a expansão da moagem da cana-deaçúcar, particularmente na Região Centro-Sul, aliada à melhoria da qualidade da matéria-prima, promoveram incrementos nos níveis de Açúcar Total Recuperável (ATR) - que representa a capacidade de a cana ser convertida em açúcar ou etanol - por tonelada de cana-de-açúcar (CONAB, 2020).

Segundo ainda a Conab, a maior disponibilidade na produção de cana-de-açúcar e o quadro conjuntural experimentado pelo açúcar possibilitaram que, majoritariamente, os ATRs anteriormente informados fossem convertidos em etanol, fazendo com que a produção daquela safra se tornasse a maior da história do setor sucroenergético nacional.

Pelo exposto denota-se a robustez do setor produtivo da cana-de-açúcar país, cujo desenvolvimento é atribuído, entre outros fatores, a projetos de incentivo do governo brasileiro como o Proálcool, à organização dos produtores do setor em entidades e à premente necessidade de fontes de combustíveis alternativas ao petróleo em nível global.

\subsection{Responsabilidade Social e diferenças conceituais}

Não existe consenso na literatura e entre os pesquisadores, quanto ao surgimento do conceito de Responsabilidade Social. Dois marcos são considerados importantes: como fato teórico o livro "O evangelho da Riqueza" de Andrew Carneiege de 1899 e, como fato político, a "ideia de função social da propriedade", inserida na constituição alemã de Weimar, em 1929. Além da evolução dos marcos políticos e teóricos surge o componente econômico, já que o liberalismo econômico do século XIX valorizava a prosperidade na iniciativa privada, com ações sociais apoiando-se em ações individuais de filantropia que, por pressões da sociedade, evoluíram no século XX para ações estratégicas de incorporação da temática social na gestão empresarial (Tenório, 2006).

Kraemer, (2006) registra que, a partir das ideias expostas, os conceitos de preservação e sustentabilidade ganharam relevância fortemente influenciados por alguns marcos importantes, como a Declaração Universal dos Direitos Humanos da ONU-Organização das Nações Unidas, a Declaração da Organização do Trabalho-OIT, as Diretrizes para as Empresas Multinacionais da Organização para a Cooperação e Desenvolvimento Econômico (OCDE), a Declaração do Rio e a Agenda 21 da ONU, entre outros.

De acordo com Clock, Heidemann, Moraes, \& Baldin, (2015), no Brasil, a responsabilidade social ganhou impulso com o advento das Organizações não governamentais (ONGs), o fortalecimento dos sindicatos e a campanha pela divulgação do Balanço Social. Na década de 1980, a sociedade experimentou períodos produtivos com a participação da sociedade em movimentos de mudança, tais como as greves, a redemocratização, "as diretas já", a nova constituinte, as conquistas da mulher, as lutas raciais e os movimentos globais em favor do meio ambiente (Vilella, 2015).

Nessa trajetória surge o conceito atual de Responsabilidade Social abalizado por um conjunto de ações e valores cujo objetivo maior é a integração de interesses corporativos, sociais e ambientais, na busca por uma sociedade mais justa, ética e com qualidade de vida, uma prerrogativa que evoluiu além das exigências legais e da sociedade, por meio de ações voluntárias das empresas em prol da sociedade, do meio ambiente e da sustentabilidade da produção (Ethos, 2000; Mariano, 2000; Tinoco, 2001; Ashley, 2003; Karkotli, 2007; Ethos, 2007; Dias, 2012; Eon, 2015).

Na concepção de Luppi, (2007), Responsabilidade Social pode ser entendida na atualidade como um fenômeno humanista estabelecido no mundo dos negócios, que não deve ser aplicado de forma isolada, mas sim como forma de gestão de um compromisso para com a sociedade, com ações efetivas de prestação de contas e transparência, um novo agir que faculta às empresas a conquista e ampliação de seu mercado, com maior competividade. 
Considerando que as demandas por uma sociedade e meio ambiente mais equilibrados estão instauradas em um cenário complexo e com exigências variadas, denota-se que as ações criadas para beneficiar a sociedade podem ter diferentes vertentes. Assim, ao longo do tempo o conceito de Responsabilidade Social ganhou incrementos e participação de mais grupos a serem contemplados, dentre eles os três principais, Responsabilidade Social Corporativa (RSC), Responsabilidade Social Empresarial (RSE) e Responsabilidade Social Ambiental (RSA), cujos conceitos, expostos nas subseções subsequentes, chegam a ser, por vezes, complementares, distintos ou até redundantes.

Criados na década de 1970 já para atender a uma demanda de responsabilização das empresas, pelo impacto gerado, ambos os termos supracitados tratam da preocupação das organizações com o ambiente de trabalho em relação a colaboradores, investidores, fornecedores e parceiros de negócios, com vistas à transparência e ética nas atividades.

Segundo Cruz, (2015), o entendimento sobre Responsabilidade Social Empresarial (RSE) perpassa pelo conceito de que as empresas devem ser responsáveis por amenizar os impactos de suas atividades junto à sociedade e ao meio ambiente. A RSE constitui-se, assim, em um compêndio de conhecimento, contribuições teóricas e práticas desenvolvidas e aprimoradas ao longo do século XX, que tem servido como guia orientador de conduta e práticas de cunho ético, moral e legal para organizações e indivíduos.

Nesse aspecto, Mendonça \& Gonçalves (2004) relevam principalmente a participação do Grupo de Institutos, Fundações e Empresas (GIFE), por se preocupar com ações sociais corporativas voltadas para o terceiro setor, e do Instituto Brasileiro de Análises Sociais e Econômicas (IBASE), pelo papel importante na mobilização e incentivo ao empresariado brasileiro em relação à publicação do Balanço Social da organização, como forma de assumir e expor sua responsabilidade social.

Os autores anteriormente especificados observam que a atuação desses institutos no sentido de mobilizar as empresas a desenvolverem ações sociais indica que as organizações, para obterem legitimidade, necessitam de adequação dos seus ambientes técnicos e institucional.

As organizações que fazem parte de um ambiente social são dependentes e necessitam de ter um status de legitimidade para o atingimento de suas ações e objetivos; e se faz necessário uma validação, que deve ser conseguida pelo apoio conferido pelos stakeholders, que apoiem e tenham uma atuação em sintonia com os objetivos e as atividades desenvolvidas (Pfeiffer \& Salancik, 1978, Brown, 1994).

Segundo Eon, (2015), diversos instrumentos de certificação foram criados nos últimos anos voltados à certificação das boas práticas empresariais. O autor observa que, na atualidade, existe uma pressão por produtos e serviços socioambientalmente corretos, o que acaba forçando as empresas na reformulação de seus processos produtivos, de forma a se adaptarem às normas impostas pelas entidades certificadoras.

\subsubsection{Responsabilidade Socioambiental}

A Responsabilidade Socioambiental se revela mais abrangente, pois considera as pessoas, colaboradores e também o meio ambiente. Tem recebido mais atenção, tanto por parte das empresas quanto da própria população.

Em um passado ainda recente, bastava às organizações, como pessoa jurídica, assumirem uma dimensão ética e socialmente responsável no cumprimento às normas e ações impostas pelas leis vigentes, voltadas ao meio ambiente e à sociedade, para melhorarem a sua imagem e ganharem o respeito das comunidades com as quais interagiam (Melo Neto \& Froes, 2001).

O contexto anteriormente exposto culminou em uma interpretação desencontrada do conceito de Responsabilidade Socioambiental. Mendonça \& Gonçalves, (2004) salientam que muitas empresas adotam ações éticas e socialmente 
responsáveis na expectativa, por vezes, de que essas ações se traduzam em preferência do público consumidor por seus produtos ou serviços. Em questionamento de pesquisa sobre Responsabilidade Social, nas empresas referidos autores indagam:

[...]. Até que ponto a imagem de socialmente responsável, transmitida por algumas empresas, reflete realmente a identidade ou a essência dessas organizações ou é apenas uma estratégia para obter legitimidade? (Mendonça \& Gonçalves, 2004, p.117).

Atualmente, muitas empresas enxergam a responsabilidade socioambiental como um grande negócio. Assim, duas vertentes se destacam nesse cenário: a primeira delas composta por empresas que investem em responsabilidade socioambiental com o intuito de motivar seus colaboradores e, principalmente, atender a um nicho de mercado que prefere pagar mais por um produto que não agride o meio ambiente e participa de ações sociais; já a segunda vertente é composta por organizações que investem em responsabilidade socioambiental com o intuito de um retorno material para investimento em marketing, preocupadas apenas com sua imagem perante os consumidores.

Diversos países que compõem a União Europeia têm criado normas para a importação de biocombustíveis, como meta de adição nos combustíveis fosseis de até $10 \%$ a partir de 2020, sendo que estas normas tendem a ser uma referência de sustentabilidade nas cadeias produtivas de etanol. O não atendimento dos critérios impostos representam fator impeditivo na exportação de etanol brasileiro para estes importantes mercados; e ainda que os consumidores externos se protejam do risco de comprar produtos, que são produzidos em situações de degradação ambiental e social (Novaes, 2009).

Segundo Nardy \& Gurgel (2013), o mercado mundial de biocombustíveis, tem apresentado um crescimento significativo e consistente nos últimos anos, e ao mesmo tempo se apresenta com muito protecionismo sob o viés ambiental e de sustentabilidade; o Brasil que tem se despontado como um grande produtor e exportador de etanol proveniente da cana de açúcar, tem que se ajustar às normativas e aspectos relacionados à sustentabilidade e, principalmente, à responsabilidade social na cadeia produtiva do etanol.

Assim, Duarte \& Malheiros, (2015) ponderam que o setor energético, de real importância para a economia brasileira, na atualidade tornou-se essencial nas discussões sobre sustentabilidade, dado o seu potencial de gerar energia renovável e contribuir, dessa forma, para a redução das emissões de gases estufa. Nesse contexto, segundo os autores, políticas públicas relacionadas a vários temas da sustentabilidade têm sido formuladas pelos governantes, para atender as prerrogativas concernentes ao desenvolvimento de referido setor.

Santos, Santos, \& Sehnem (2016), corroboram a sustentabilidade como temática central em conferências, debates e fóruns a partir dos movimentos ambientalistas da década de 1960, voltados não só à questão ambiental, como também aos problemas sociais e econômicos.

Vários são os desafios da sustentabilidade hoje, dentre eles a implementação de normas de proteção ambiental, a captura dos impactos externos das atividades além do nível local, o reconhecimento da sustentabilidade social, o desenvolvimento humano, a produção e o consumo equilibrado, o incentivo à educação, desenvolvimento e manutenção de recursos ambientais, cooperação entre stakeholders, governos e sociedade civil, metodologias e indicadores de sustentabilidade de acesso público, pesquisas aplicadas e que tragam resultados práticos, indicadores voltados para os sistemas empresariais locais, entre tantos outros desafios que possam contribuir para a viabilização da prática da sustentabilidade (Sartori, Latronico, \& Campos, 2014; Santos, Santos, \& Sehnem, 2016; Andion, Alperstedt, \& Graeff, 2020).

Pelo exposto denota-se que a sustentabilidade, além das atividades produtivas, envolve o tratamento voltado ao meio ambiente, ao relacionamento com fornecedores, público interno e externo e com a sociedade e às práticas de governança corporativa, transparência e postura de forma a agregar valores éticos de extrema valia na atualidade. 


\subsection{Indicadores de Mensuração de Ações de Responsabilidade Social no Setor Sucroenergético}

Santos, Santos, \& Sehnem, (2016) corroboram as concepções de Vasconcelos, Andrade, \& Cândido (2009) no tocante à complexidade da construção e uso de indicadores de sustentabilidade, uma vez que referidos indicadores têm a função, a princípio, de demonstrar a relação da sociedade com o meio ambiente numa perspectiva ampla, cujo processo envolve inúmeras variáveis. Ponderam os autores que há que se adotar uma postura sistêmica para que haja uma melhor compreensão da realidade dos fatos, dada a mútua influência dos elementos envolvidos.

Pelos referenciais expostos denota-se a demanda por planejamento e controle na mensuração do que foi previamente programado e do que está sendo efetivamente alcançado é de suma importância, já que organizações e organismos governamentais lançam mão do resultado dos indicadores criados e adotados por eles para demonstrar à sociedade o grau de comprometimento com as boas práticas sustentáveis.

Em relação aos indicadores, alguns já são amplamente conhecidos como é o caso do índice Dow Jones Sustainability, Índice de Sustentabilidade Empresarial Bovespa, Ethos, Ibase, novas normas como OSHAS 18001 e ISO 26000, além do emprego de novas iniciativas como o Pacto Global da ONU e o Global Reporting Initiative, dentre outros (Mastroti \& Souza, 2011).

Raufflet, (2008), entretanto, considera que, sem desmerecimento aos demais conjuntos de indicadores, o Ethos destaca-se de forma exímia por sua dimensão transcender, na concepção do autor, a simples organização típica relacionada a negócios para se assemelhar mais a um "movimento social".

O Instituto Ethos de Empresas e Responsabilidade Social é uma organização sem fins lucrativos criada em 1998 por lideranças do setor empresarial com a missão de "mobilizar, sensibilizar e ajudar as empresas a gerir seus negócios de forma socialmente responsável, tornando-as parceiras na construção de uma sociedade justa e sustentável” (Ethos , 2007, p.4).

Para Aligleri (2011), a missão do Instituto Ethos é pautada pela mobilização, sensibilização e auxílio às empresas na gestão de seus negócios de forma socialmente responsável, formando parcerias na construção de uma sociedade mais sustentável e justa (Ethos , 2007).

Cruz(2015) especifica que os Indicadores Ethos de Responsabilidade Social Empresarial (RSE) auxiliam empresas na gestão socialmente responsável de seus negócios e, especificamente, uma de suas dimensões, a do Meio Ambiente, trata dos temas relativos à gestão ambiental.

A promoção do debate e difusão de práticas de Responsabilidade Social Corporativa (RSC) permitiu ao Ethos responder a questões cruciais brasileiras como a reforma do Estado, a corrupção, os desafios ambientais e urbanos. Na opinião de (Raufflet, 2008), esses aspectos configuram ao Ethos, simultaneamente, a característica de uma organização localmente relevante, ao mesmo tempo em que fornece um importante elo para os debates internacionais sobre a RSC.

A inovação é impulsionada pela capacidade de detectar conexões, com o objetivo de identificar oportunidades de realizar melhorias nos produtos, processos e produtos; conseguir transformar ideias em uma realidade aproveitável, e não apenas por meio de novos mercados, mas também nos mercados existentes (Bessant \& Tidd, 2009).

Segundo Nidumolu, Prahalad, \& Rangaswami, (2009), o cumprimento de uma regulação, direciona a inovação, como uma oportunidade de negócio, por meio da tecnológica, matérias e processos sustentáveis; de outro lado Nill \& Kemp, (2009) consideram que uma regulação ambiental não é suficiente para a promoção de uma inovação sustentável, e que existem relações ínfimas na conexão das inovações com a responsabilidade social; ainda que para um desenvolvimento sustentável, se faz necessário, mudanças radicais em tecnologia e nos sistemas de inovação; finalmente os autores enfatizam que inovação incremental em setores já consolidados, não e' suficiente para atender uma demanda social de metas de sustentabilidade ambiental e a própria mitigação das mudanças climáticas 
Cirani \& Moraes (2010) tomam por referência a OCDE, (2007) ao registrarem a relevância do desenvolvimento e difusão de novas tecnologias no crescimento da produção e aumento da produtividade. Segundo as autoras, a inovação tecnológica é o elemento-chave para a indústria enfrentar a abertura da economia e buscar a melhor inserção no mercado mundial.

Mesmo com tal valia, denota-se que a conexão entre Inovação e Responsabilidade Social nas organizações não tem ocorrido de forma plena. Nesse sentido, Cardona, (2011) cita a Teoria da Firma, de Alfred Marsall e o estudo de Penrose, (1959), cuja distinção entre empresa inovadora e empresa otimizadora permite observar que a inovação exige uma ação participativa, que requer a colaboração de diferentes capacidades, em contexto interdisciplinar e coletivo difícil de mensurar (Malaver \& Vargas, 2007; Siqueira, 2013; Andrade, 2017).

Para Horbach (2005), mesmo com as diferenças conceituais e terminologias nos termos utilizados nas iniciativas de inovação centradas em aspectos de sustentabilidade, alguns elementos da própria teoria de inovação embasam os condicionantes neste tipo de inovação, orientados pela oferta/demanda e pela influência política e institucional (Pinsky, Moretti, Kruglianskas, \& Plonski, 2015).

Cardona, (2011) aponta quatro vínculos básicos entre inovação e responsabilidade social empresarial, a saber: inovação social, inovação organizacional, a relação entre inovação e empreendimento e o conceito de inovação disruptiva. O ponto de encontro mais desenvolvido entre inovação e RSE situa-se na inovação disruptiva, por meio da qual se transferem benefícios às pessoas, em países em desenvolvimento, por meio de companhias multinacionais, que realizam atividades na base da pirâmide social (Prahalad \& Hart, 2002; Garriga \& Melé, 2004).

Segundo concepção de Prahalad \& Hart (2002), ratificada por Raufflet \& Do-amaral (2007), a inovação organizacional em alguns grupos empresariais tem desenvolvido mecanismos para gerar impacto social positivo, contudo com um viés mais filantrópico; neste tipo de inovação destacam-se no Brasil o Instituo Ethos e a Fundação Abrinq, que realizam atividades efetivas em diversas comunidades carentes.

Existem fortes nexos entre Inovação e Responsabilidade Social que ainda estão em construção por apresentarem alto nível de complexidade, já que exigem pluralidade de abertura e alianças entre grupos humanos antagônicos (político e econômico), com a aplicação da inovação em distintas esferas, das empresas tradicionais com produtos e serviços que são dirigidos a novos mercados e que possuem um potencial de gerar benefícios econômicos e de bem-estar tanto para as empresas, como para as organizações da sociedade civil, e principalmente para as populações de baixa renda (Cardona, 2011).

Schaltegger, (2011) elencaram três razões fundamentais para a inovação sustentável quando relacionada ao benefício privado de redução de custos e o benefício social que é gerado, a saber: 1) o benefício privado é maior do que o impacto negativo gerado pela inovação; 2) uma inovação tem um impacto social positivo maior do que o benefício privado; e, 3) os benefícios privado e social se equiparam.

De acordo com Pinsky, Moretti, Kruglianskas, \& Plonski (2015), tanto na literatura nacional como internacional, não existe uma padronização sobre os principais conceitos das ligações entre Inovação e Responsabilidade Social. Sob essa perspectiva, referidos autores realizaram uma consolidação dos termos utilizados, conforme Quadro1: 
Quadro 1 - Principais diferenças conceituais entre Inovação e Sustentabilidade.

\begin{tabular}{|l|l|}
\hline Inovação Sustentável & $\begin{array}{l}\text { Abordagem de nichos tecnológicos; considera mudanças tecnológicas } \\
\text { e sociais concomitantemente. }\end{array}$ \\
\hline Inovação Ambiental & $\begin{array}{l}\text { Orientada predominantemente por regulação ambiental; visa à } \\
\text { redução de custo; não aprofunda na análise do ciclo de vida. }\end{array}$ \\
\hline Eco inovação & $\begin{array}{l}\text { Considera o impacto e avaliação do ciclo de vida; inovação } \\
\text { tecnológica, social e institucional; prioriza o desempenho ambiental } \\
\text { em detrimento à meta ambiental. }\end{array}$ \\
\hline Inovação verde & $\begin{array}{l}\text { O desempenho da inovação considera o posicionamento da empresa e } \\
\text { imagem verde; não aprofunda na análise do ciclo de vida. }\end{array}$ \\
\hline
\end{tabular}

Fonte: Pinsky et al. (2015, p.233).

Corrêa, Sacomano Neto, Spers, \& Giuliani (2010) observam que são dois os principais e robustos desafios que o paradigma de desenvolvimento sustentável traz para as empresas, a saber: gerar inovações sustentáveis necessárias à existência humana e assegurar a aceitação de novos produtos e serviços pela sociedade. Para os autores, frente ao desafio de levar as futuras tecnologias e inovações tecnológicas a impulsionar negócios mais sustentáveis, que podem propiciar às empresas novas opções de criação de valor, torna-se crucial descobrir novas formas para as empresas que atuam em ambientes cada vez mais complexos, incorporarem a visão de sustentabilidade econômica, social e ambiental - igualmente complexa - em suas estratégias tecnológicas.

Corrêa, Sacomano Neto, Spers, \& Giuliani (2010) justificam que as tecnologias que impulsionarão negócios bemsucedidos e sustentáveis serão aquelas que, desde a formulação da estratégia tecnológica até as etapas finais do processo de Pesquisa e Desenvolvimento (P\&D) e de inovação tecnológica incorporarão os valores éticos da sustentabilidade.

Milanez, Souza, \& Mancuso (2017), em pesquisa para o BNDES sobre o panorama setorial sucroenergético com projeção para 2030, registram que a biotecnologia industrial e agrícola tem se beneficiado da evolução de duas tecnologias genéricas: tecnologia da informação e robótica. A primeira permitiu a evolução dos estudos e pesquisas que necessitam de uma capacidade elevada de processamento de dados. Já a segunda proporciona a capacidade crescente de realização de testes de seleção e melhoramento de organismos geneticamente modificados.

Como resultado, segundo os autores anteriormente mencionados, há evolução em diversas tecnologias com aplicação na indústria do etanol, por exemplo: novos conhecimentos baseados em engenharia genética, biologia de sistemas e novos processos fermentativos e enzimáticos; biologia sintética como uma poderosa ferramenta que pode permitir o desenho de rotas metabólicas inovadoras; serviços de mapeamento genético; enzimas mais eficientes para hidrólise da biomassa; novos microrganismos com diferentes especialidades funcionais; melhoramento genético da cana-de-açúcar; introdução de novas culturas, mais energéticas, como a cana-energia. Está em curso atualmente uma corrida tecnológica internacional pelos biocombustíveis lignocelulósicos, tal como o E2G. A produção desses biocombustíveis representa uma inovação significativa, uma vez que envolve plataformas científicas de fronteira, como a biotecnologia.

A química verde também surge como alternativa promissora para a agregação de valor para as empresas do setor sucroenergético. A alcoolquímica e a sucroquímica tornam possível a conversão de etanol e açúcares da cana em produtos e 
intermediários químicos, como o farneseno, o eteno e o butanol. Por essa razão, empresas do setor petroquímico, como Braskem, Dow e Dupont, estão se voltando para pesquisas na área da química verde. Especificamente no Brasil, muitas dessas empresas têm buscado parcerias com as usinas processadoras de cana (Milanez, Souza, \& Mancuso, 2017).

\subsection{Perspectivas para o Setor Sucroenergético Brasileiro}

Garcia, Lima, \& Vieira (2015) registram que o setor sucroenergético brasileiro tem atraído investimentos estrangeiros de forma acentuada desde 2003/2004. Para os autores os fatores que estimularam este movimento estão relacionados às perspectivas de consolidação de um mercado internacional, à expansão da demanda externa e interna e à elevação do preço do combustível fóssil. Na concepção dos mesmos, outro fator que contribui para a atratividade do capital externo é a competitividade do etanol brasileiro em relação às demais matérias-primas utilizadas em outros países.

Silva (2015) corrobora o exposto a partir do resultado de pesquisa aplicada em especialistas do setor sucroenergético, escolhidos com o auxílio da abordagem de sistemas setoriais de inovação, com o objetivo de identificar e analisar as oportunidades de inovação no setor sucroenergético. Segundo a autora, as oportunidades que mais foram destacadas pelos entrevistados foram aquelas voltadas à produção do etanol de segunda geração, à venda de bioeletricidade e à geração de novos produtos a partir de fonte renovável. Os especialistas listaram os aspectos ambientais, financeiros e organizacionais como os principais fatores responsáveis por impulsionar referidas inovações. Dentre os fatores inibidores apontados estão a grande dificuldade de comunicação entre os agentes da área de pesquisa e indústria, e outros fatores de origem tecnológica, política e organizacional.

Chueri \& Santos (2019) alertam sobre a necessidade de criação de soluções tecnológicas de suporte principalmente aos atores da Inovação Social, com vistas ao fomento da colaboração, cocriação e compartilhamento de conhecimento e competência. Para os autores, este apoio pode facilitar a condução de projetos de inovação social, geração de inovações sociais mais efetivas e utilização eficaz de todo conhecimento adquirido.

Para Carvalho \& Oliveira (2006), no médio e longo prazo, as perspectivas para o setor sucroalcooleiro são favoráveis. Esse cenário é sustentado pela competitividade da produção brasileira de açúcar e álcool, pela modernização do parque produtivo nos últimos anos e pelas pressões ambientalistas para utilização de combustíveis renováveis e mais limpos. De acordo com os autores, desafios como a melhoria da infraestrutura para o escoamento da produção (dutos e estradas de ferro) e a própria coordenação da cadeia produtiva, evitando o desbalanceamento do mix de produção (muito álcool ou muito açúcar).

Tranin (2020) destaca que o setor sucroalcooleiro vem se recuperando depois de um longo e difícil período de crise financeira provocada pelo congelamento do preço da gasolina por anos e pelo aumento da produção mundial de açúcar, com retração do mercado, em situação que levou ao fechamento de cerca de 100 empresas sucroenergéticas no Brasil e deixou muitas unidades em situação delicada em todo o país. Tranin (2020) também evidencia que é possível vislumbrar uma recuperação do setor face às elevações no preço internacional do petróleo e à variação cambial, com o dólar mais alto, bem como influenciada pelas mudanças positivas da política governamental, com o preço da gasolina acompanhando as oscilações de preços do mercado internacional de petróleo e principalmente com o RenovaBio, a nova Política Nacional de Biocombustíveis, instituída pela Lei $\mathrm{n}^{\circ}$ 13.576/2017, cujo objetivo é expandir a produção de biocombustíveis no Brasil, baseada na previsibilidade, na sustentabilidade ambiental, econômica e social, e compatível com o crescimento do mercado, em situação que permite maior competitividade em relação à gasolina, e que resultou na produção e comercialização recorde de etanol em 2019. 
Research, Society and Development, v. 10, n. 4, e32610414317, 2021

(CC BY 4.0) | ISSN 2525-3409 | DOI: http://dx.doi.org/10.33448/rsd-v10i4.14317

\section{Resultados e Discussão}

Os resultados da pesquisa são apresentados sequencialmente, a partir dos dados qualitativos coletados. Em razão da quantidade deles, procurou-se estruturar a seção conforme os objetivos do estudo.

Por se adequarem mais aos objetivos propostos, as modalidades selecionadas pelo software Iramuteq para o presente estudo foram a "Análise de Similitude" e a análise por "Nuvem de Palavras", expostas na sequência.

A partir dos vocábulos mais citados ao longo dos 50 trabalhos analisados, o software IRAMUTEQ selecionou um universo de 4.200 palavras com base nas palavras-chaves colocadas à disposição do mesmo (conforme Figura 1).

A partir da Figura 1 o software IRAMUTEQ gerou imagens em cores (Figuras 2 e 3), projetadas através de indicadores estatísticos das inter-relações entre os vocábulos selecionados, como resultado da "Análise de Similitude".

Figura 2. Resultado da Análise de Similitude.

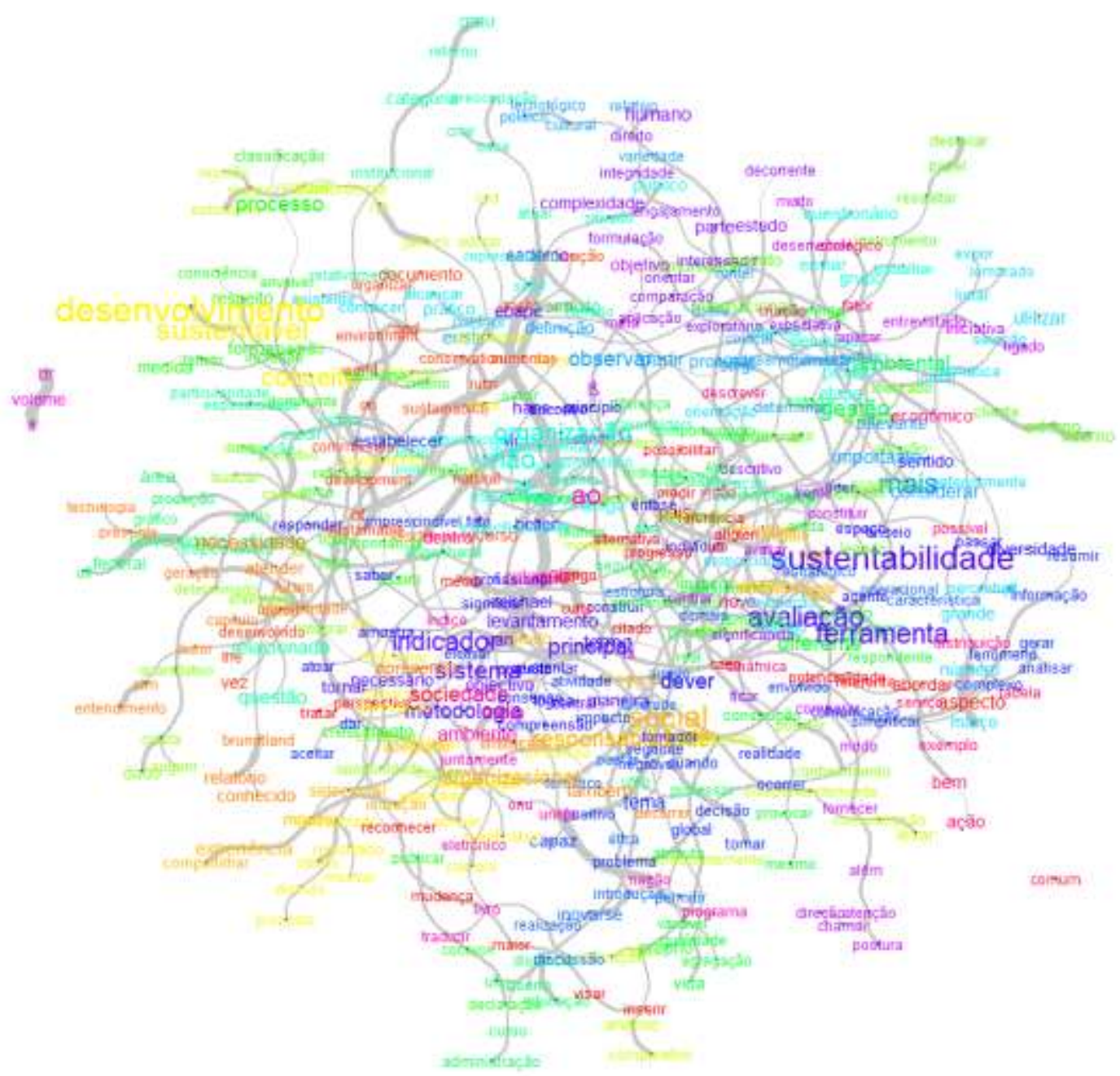

Fonte: Elaboração própria (2020). 
Figura 3. Resultado da Análise de Similitude (II).

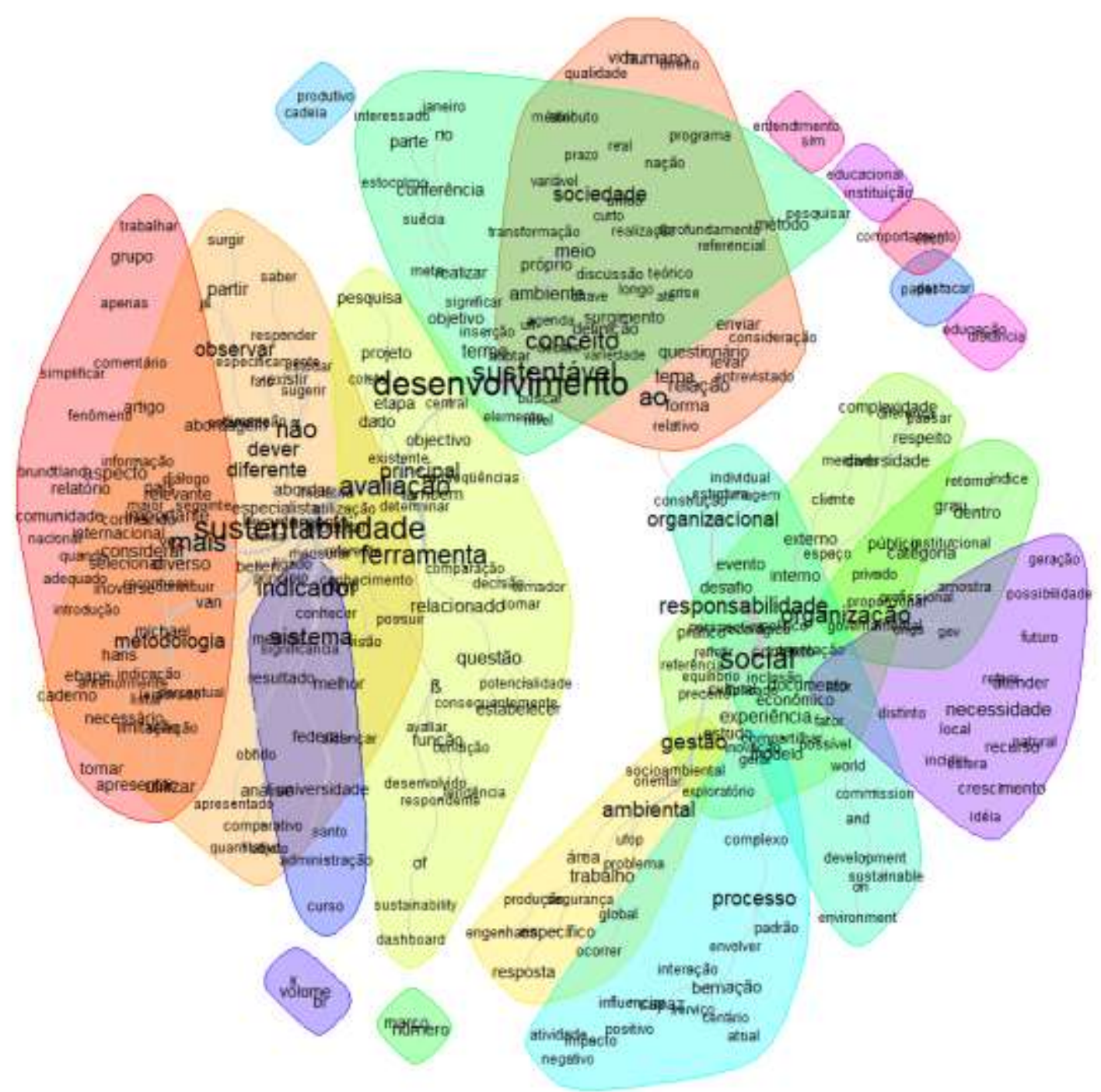

Fonte: Elaboração própria (2020).

Os resultados da Análise de Similitude (Figuras 2 e 3) revelam, a partir da concentração de cores e tamanho da grafia do vocábulo exposto, a força do mesmo em relação ao fator de repetição nos artigos pesquisados, ou seja, confirmam que são palavras que compõem os trabalhos analisados, têm maior representatividade nos mesmos e são em quantidade suficiente para gerar a concentração de cores e a expressividade maior na grafia.

A evidência de contextos com significados demarcados em cada um dos campos de cores traz indicação da conexidade entre si e sinaliza a comunicação e a interdependência entre as temáticas mais representativas do universo pesquisado.

As duas figuras que emergem do software são autoexplicativas, na identificação das palavras e temáticas que são relevantes nos artigos que foram analisados, com destaque para: desenvolvimento sustentável, sustentabilidade, responsabilidade social, indicadores, sociedade. 


\section{Nuvem de Palavras da Análise de Conteúdo}

$\mathrm{Na}$ continuidade da validação dos resultados a partir de dados tratados pelo IRAMUTEQ depreende-se que os vocábulos mais frequentemente destacados na Nuvem de Palavras ratificam uma vez mais as temáticas envolvidas na pesquisa bibliográfica e documental empreendida.

Dessa forma, o cenário exposto na Figura 4 subsequente (Nuvem de Palavras) é emblemático por justificar a relevância dos termos destacados nos trabalhos pesquisados, no período 2000-2020.

Figura 4. Resultado da Nuvem de Palavras.

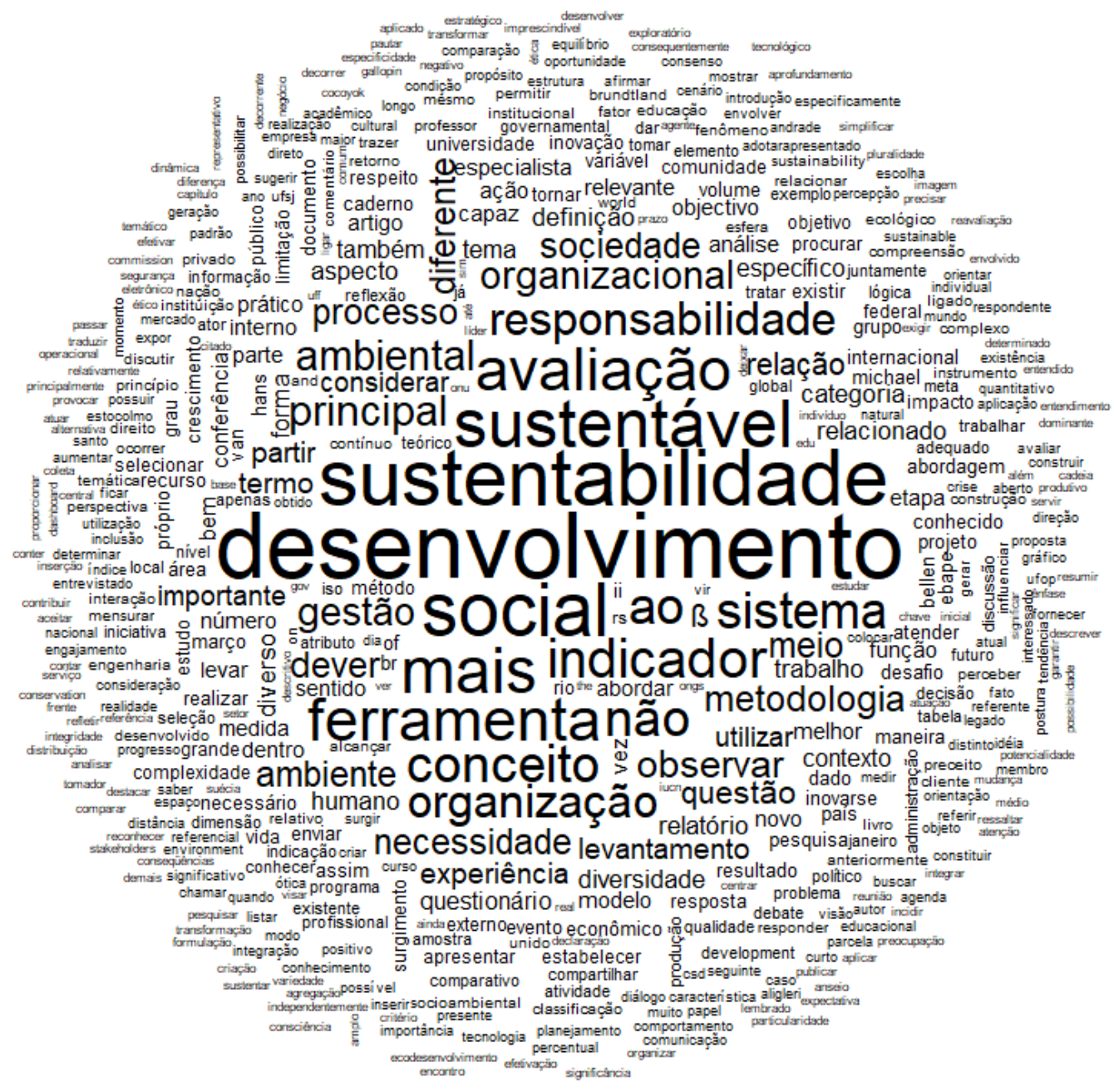

Fonte: Elaboração própria (2020).

O exposto na análise de conteúdo pela Nuvem de Palavras corrobora os resultados explicitados anteriormente nas Análises de Similitude, já que ambas projetam evidências de identificação de vocábulos que se destacam de forma muito semelhante. Referida conexidade permite validar o rigor metodológico e estatístico do software IRAMUTEQ, não só no tocante ao resgate de dados, mas principalmente no que se refere à otimização da organização e confiabilidade dos mesmos (Camargo \& Justo, 2013; Pinto, Mazieri \& Vils, 2017).

As mesmas palavras que emergem das Figuras 2 e 3 são confirmadas pelo Resultado da Nuvem de Palavras da Figura 4, como sendo: desenvolvimento social, indicadores, ferramentas, avaliação, sustentável, sociedade e organizacional. 


\section{Considerações Finais}

A motivação do presente estudo está associada ao interesse de um acompanhamento mais acurado dos avanços e expansão da ciência e tecnologia nas últimas duas décadas do século em curso, por meio da análise de trabalhos cujas abordagens teóricas pudessem fornecer subsídios sobre temáticas voltadas à Responsabilidade Social, Sustentabilidade e Inovação, dentre outras, com vistas à identificação dos caminhos que o conhecimento percorreu ao longo do tempo especificado.

A revisão bibliográfica indica uma consolidação dos conceitos de Responsabilidade Social nas empresas em geral, no setor sucroenergético em especial, as ações concretas vêm sendo incorporadas à maior parte das empresas nos últimos anos; embora não exista um padrão que vem sendo seguido, com empresas imprimindo ações mais efetivas e outras praticamente que não possuam a responsabilidade social no seu dia a dia.

Esta temática abordada da Responsabilidade Social no setor sucroenergético está em processo de construção, e vem se consolidando como uma vertente cada vez mais importante para as empresas do setor, em especial aquelas que tem buscado o mercado externo para exportação de seus produtos, principalmente o etanol da cana de açúcar, como um aditivo para os combustíveis, por ser um produto renovável e com efeitos importantes no combate à poluição dos países mais desenvolvidos.

As empresas produtoras de açúcar e etanol no Brasil tem uma elevada competitividade em seus produtos, com alto potencial de conquistar mercados, principalmente pelas vantagens competitivas existentes no pais, como: clima, solo, regime de chuvas, tecnologia, escala de produção, entre outros fatores. Os aspectos relacionados com a Responsabilidade Social nas suas vertentes de relações no trabalho, sustentabilidade ambiental e ações afirmativas na sociedade representar uma fraqueza relevante para este setor, principalmente pela falta de inclusão do tema na estratégia da grande maioria das empresas.

Assim, num contexto de prospecção na própria literatura, o texto busca encontrar conexões que possam existir entre a Responsabilidade Social e os aspectos de inovação existente nas empresas do setor sucroenergético; os resultados encontrados na literatura se mostram incipientes, não existindo relações significativas no sentido que empresas mais inovadoras possuem uma maior Responsabilidade Social; entretanto, as empresas começam a ter a percepção da importância não só dos aspectos da responsabilidade social, mas principalmente dos diferentes aspectos de inovação, principalmente a inovação incremental em processos, em gestão, aproveitamento e solução para seus resíduos, e ainda, nas suas interações com a sociedade.

Neste contexto emergiu o objetivo deste estudo, de compilar e expor breve síntese de ideias, tendências e perpectivas concernentes ao setor sucroenergético, tendo como escopo a Análise de Conteúdo (AC), voltada à revisão da literatura sobre os temas anteriormente especificados, envolvidos no setor de produção de açúcar e álcool no país.

O uso do Software de Análise Textual IRAMUTEQ como ferramenta de apoio à pesquisa para a análise léxica automatizada em Administração de Empresas foi um diferencial no estudo, já que na atualidade referido software é mais comumente utilizado em pesquisas qualitativas produzidas no âmbito dos programas de pós-graduação nas Áreas de Ciências Humanas, Ciências Sociais e da Saúde (Camargo \& Justo, 2013; Pinto, Mazieri \& Vils, 2017).

$\mathrm{O}$ artigo permeia uma temática com uma amplitude de conceitos que ainda estão em processo de consolidação no setor sucroenergético, utilizando-se de uma ferramenta tecnológica, como o IRAMUTEC, para conseguir buscar novos horizontes e principalmente tentar encontrar na literatura tendências e conexões que possam existir nos diferentes aspectos da Responsabilidade Social e suas relações com aspectos de inovação.

As restrições do presente artigo estão ligadas aos aspectos da subjetividade existente por parte dos autores na escolha das palavras chave de busca dos artigos que são selecionados para serem analisados pelo software, bem como da própria escolha dos artigos que são analisados

A própria analise dos resultados obtidos pelo software, entende-se como uma restrição ao presente artigo, uma vez que os resultados são apresentados por uma nuvem de palavras e uma análise de similitude; situação em que somente palavras 
são apresentadas; o próprio esforço dos autores em realizar este tipo de análise e apresentar conclusões está sujeito a erros de interpretação; neste sentido, a própria revisão bibliográfica preliminar se apresenta no sentido de minimizar estes possíveis erros, mas mesmo assim, continua presente.

Novas linhas de pesquisa se apresentam a partir do presente artigo, para mensurar de que maneira as empresas do setor sucroenergético estão avançando nos aspectos da Responsabilidade Social no Brasil, em especial nas suas relações do trabalho; ainda a realização de estudos comparativos da situação brasileira com outros países; finalmente uma linha de pesquisa nos impactos do Renovabio, um importante programas brasileiro de descabonização, que começou a ser operacionalizado em 2020, pela venda dos Cbios (1 tonelada de carbono capturado da atmosfera), na Bolsa de Valores brasileira B3

Infere-se que o objetivo foi alcançado, tanto através da revisão bibliográfica e documental que possibilitou caracterizar as variáveis da pesquisa pelo diferencial do uso de modelos teóricos que se mostraram adequados à realidade e que poderão ser explorados em outros estudos, como pela possibilidade de apurar o quão extenso tem se tornado o campo da Administração nas últimas décadas, em situação que configura não somente a consolidação da Administração enquanto área do conhecimento, como a abertura para futuras indagações pertinentes a esse campo de estudo.

\section{Referências}

Aligleri, \& Borinelli, B. (set. de 2001). Responsabilidade Social nas grandes empresas da região de Londrina. Encontro da ANPAD- Associação Nacional dos Programas de Pós-graduação em Administração.

Aligleri, L. M. (2011). A adoção de ferramentas de gestão para a sustentabilidade e a sua relação com os princípios ecológicos nas empresas. São Paulo: Tese (Doutorado em Administração) -Departamento de Administração da Faculdade de Economia, Administração e Contabilidade. São Paulo: Universidade de São Paulo.

Andion, C., Alperstedt, G. D., \& Graeff, J. F. (fev. de 2020). Ecossistema de inovação social, sustentabilidade e experimentação democrática: um estudo em Florianópolis. Revista de Administração Pública, pp. 1881-200.

Andrade, M. C. (2017). Inovações Tecnológicas no Setor Sucroalcooleiro: Determinantes, Estágio Vigente e Perspectivas no Contexto Brasileiro (2005-2014). Revista Brasileira de Gestão e Inovação - Brazilian Journal of Management \& Innovation, pp. 89-106.

Ashley, P. A. (2003). Ética e responsabilidade social nos negócios. Saraiva.

Bardin, L. (2011). Análise de conteúdo. Educações.

Bessant, J., \& Tidd, J. (2009). Inovação e empreendedorismo. Bookman Editora, 2009. Bookman.

Bignetti, L. (2011). As inovações sociais: uma incursão por ideias, tendências e focos de pesquisa. Ciências Sociais Unisinos, v.47(1):3-14, 2011. Ciências Sociais Unisinos, pp. 3-14.

Brown, A. D. (1994). Politics, symbolic action and myth making in pursuit of legitimacy. Organization Studies, pp. 861-878.

Câmara, M. R., \& Caldarelli, C. E. (2016). Expansão canavieira e o uso da terra no estado de São Paulo. Estudos Avançados, pp. $93-116$.

Camargo, B. V., \& Justo, A. M. (2013). Iramuteq: Um software gratuito para análise de dados textuais. Temas em Psicologia, pp. 513-518.

Cardona, H. A. (2011). Innovación y responsabilidad social: una reflexión sobre los puntos de encuentro. Revista Universidad y Empresa, pp. 13-35.

Carvalho, F. S. (2012). O setor sucroenergético no Brasil: Estado, hegemonia e relações internacionais . Dissertação (Mestrado) - Universidade Estadual Paulista, Faculdade de Filosofia e Ciências. 2012. .

Carvalho, G. R., \& Oliveira, C. d. (2006). O setor sucroalcooleiro em perspectiva. Embrapa Territorial-Circular Técnica (INFOTECA-E).

Castillo, R. (2016). Dinâmicas recentes do setor sucroenergético no Brasil: competitividade regional para o bioma Cerrado. GEOgraphia , pp. 17-35.

Chueri, L. O., \& Santos, R. C.-S. (2019). Caracterização e Gerenciamento de Ecossistemas Digitais de Inovação Social. Workshop de Teses e Dissertações em Sistemas de Informação - Simpósio Brasileiro de Sistemas de Informação (SBSI). Aracaju: Anais.

Cirani, C. B., \& Moraes, M. A. (dez. de 2010). Inovação na indústria sucroalcooleira paulista: os determinantes da adoção das tecnologias de agricultura de precisão. Revista Economia Social Rural, pp. 543-565.

Clock, D., Heidemann, A., Moraes, A., \& Baldin, N. O. (2015). Conhecimento, Responsabilidade Social e Sustentabilidade -Pilares para a cidadania no século XXI. VI Congresso Brasileiro de Gestão Ambiental. Porto Alegre. 
Companhia Nacional de Abastecimento (CONAB) (2020). (Abril de 2020). <http://www.conab.gov.br/chromeextensi. Fonte: CONAB. Companhia nacional de abastecimento. Monitoramento Agrícola - Cana-de-Açúcar -Acompanhamento de safra brasileira de cana - Quarto levantamento, abril 2020 - v.6 safras 2019/2020: <http://www.conab.gov.br/chromeextension://oemmndcbldboiebfnladdacbdfmadadm/https://www.conab.gov.br/info-agro/safras/cana/boletim-dasafra-de-cana-de-acucar/item/do

Corrêa, D., Sacomano Neto, M., Spers, V., \& Giuliani, A. (set./dez. de 2010). Sustentabilidade e Responsabilidade Social: análise da experiência de uma empresa de equipamentos pesados. Revista de Gestão Social e Ambiental, pp. 90-105.

Cruz, J. (2015). Gestão Ambiental à luz da Responsabilidade Social Empresarial: Um estudo no setor sucroenergético em Goiás. IV SINGEP - Simpósio Internacional de Gestão de Projetos, Inovação e Sustentabilidade. São Paulo.

Dalfovo, M. S., Lana, R., \& Silveira, R. (2008). Métodos quantitativos e qualitativos: um resgate teórico. Revista Interdisciplinar Científica Aplicada, 1-13.

Dias, R. ( 2012). Responsabilidade Social: fundamentos e gestão. Atlas.

Domeneghetti, D., \& Meir, R. (2009). Ativos Intangíveis, o Real Valor das Empresas. Campus Elsevier.

Duarte, C., \& Malheiros, T. (set./dez. de 2015). Sustentabilidade e Políticas Públicas para o Setor Sucroenergético: uma análise dos temas abordados. Revista de Gestão Ambiental e Sustentabilidade.

Eon, F. (2015). O que é Responsabilidade Social?. Acesso em 31 de out. de 2020, disponível em Revista ResponsabilidadeSocial.Com: http://www.responsabilidadesocial.com/o-que-e-responsabilidade-social/>

Ethos. (2000). Indicadores Ethos de Responsabilidade Social Empresarial. Instituto Ethos.

Ethos, (2007). O que é RSE? Acesso em 31 de out. de 2020, disponível em Instituto Ethos: https://www.ethos.org.br/cedoc/conceitos-basicos-eindicadores-de-responsabilidade-social-empresarial-5a-edicao-2/.

Gilnberg, G. (1980). Introdução aos problemas da poluição ambiental. EPU.

Furtado, A., Scandiffio, M., \& Cortez, L. (2010). The Brazilian Sugarcane innovation system. Energy Policy, pp. $156-166$.

Garcia, J. R., Lima, D. A., \& Vieira, A. C. (abril de 2015). A nova configuração da estrutura produtiva do setor sucroenergético brasileiro: panorama e perspectivas. Revista Economia Contemporânea, pp. 162-185.

Garriga, E., \& Melé, D. (2004). Corporate social responsability teories: mapping the territory. Journal of Business Ethics, pp. 51-71.

Gil, A. C. (2008). Como elaborar projetos de pesquisa. Atlas.

Godoy, A. S. (1995). Introdução à pesquisa qualitativa e suas possibilidades. Revista de Administração de Empresas, 57-63.

Horbach, J. (2005). Indicator systems for sustainable innovation. Physica-Verlag.

Karkotli, G. (2007). Responsabilidade Social Empresarial (2a ed.). Vozes.

Kraemer, M. E. (2006). Marco referencial da responsabilidade social corporativa. GESTIPOLIS 2006. Disponível em: <http://www.gestiopolis.com/canales5/fin/marcore.htm>. Acesso em nov.2020.

Kripka, R. M., Scheller, M., \& Bonotto, D. L. (2015). Pesquisa documental na pesquisa qualitativa: conceitos e caracterização. Revista de investigaciones UNAD, v. 14, n. 1, p. 55-73, 2015. Revista de investigaciones UNAD, 14(1), 55-73.

Luppi, L. (2007). Responsabilidade Social x Motivação. Responsabilidade Social. Acesso em 29 de out. de 2020, disponível em resposabilidadesocial.com: <http://www.responsabilidadesocial.com/artigo/responsabilidade-social-X-motivacao/>

Malaver, F., \& Vargas, M. (2007). Los procesos de innovación en la industria colombiana: aportes para su caracterización. Organización de Estados Americanos, 2007. <Http://www.science.oas.org/ricyt/interior/normalizacion/VItaller/S6_\%20Innov/Malaver_Vargasdoc.Pdf. A.

Mariano, R. P. (ago./out. de 2000). Elementos principais dos diferentes modelos propostos de Balanço Social. Pensar Contábil, 9.

MastrotI, R. R., \& Souza, D. G. (2011). Sustentabilidade \& produção: teoria e prática para uma gestão sustentável. Atlas.

Melo Neto, F. D., \& Froes, C. (2001). Gestão da responsabilidade social corporativa: o caso brasileiro. Qualitymark.

Mendonça, J. R., \& Gonçalves, J. C. (2004). Responsabilidade social nas empresas: uma questão de imagem ou de essência? Organizações \& Sociedade, 115130 .

Milanez, A. Y., Souza, J. A., \& Mancuso, R. V. (2017). Panoramas setoriais 2030: desafios e oportunidades para o Brasil. Banco Nacional de Desenvolvimento Econômico e Social.

Moraes, M. A., \& Zilberman, D. (2014). Production of ethanol from sugarcane in Brazil. Springer.

Nardy, V., \& Gurgel, A. C. (2013). Impactos da liberalização do comércio de etanol entre Brasil e Estados Unidos sobre o uso da terra e emissão de CO2. Nova Economia, 693-726.

Nidumolu, R., Prahalad, C. K., \& Rangaswami, M. R. (2009). Why sustainability is now the key driver of innovation. Harvard business review, 56-964.

Nill, J., \& Kemp, R. (2009). Evolutionary approaches for sustainable innovation policies: From niche to paradigm? Research policy, 668-680. 
Novaes, E. N. (2009). Responsabilidade Social e abertura de capitais: uma descrição dentro do complexo agroindustrial canavieiro do Brasil. Dissertação (Mestrado em Engenharia de Produção) - Programa de Engenharia de Produção da Universidade Federal de São Carlos, São Carlos.

Organização de cooperação para o desenvolvimento económico (OCDE) (2007). Manual de Oslo. Diretrizes para coleta e interpretação de dados sobre inovação. Organização de cooperação para o desenvolvimento económico, Oslo.

Oliveira, B., \& Gouvea, M. A. (2010). A importância das ações sociais empresariais nas decisões de compra dos consumidores. Gestão Produção , 791-800.

Pelegrin, I., \& Antunes Jr, J. A. ( 2013.). Gestão da inovação e competitividade no Brasil: da teoria à prática. Bookman.

Penrose, E. (1959). The theory of the growth of the firm. Oxford University Press.

Pfeiffer, J., \& Salancik, G. R. (1978.). The external control of organizations: a resource dependence perspective. Harpes \& Row.

Pinsky, V. C., Moretti, S., KruglianskaS, I., \& Plonski, G. (2015). Inovação sustentável: uma perspectiva comparada da literatura internacional e nacional. RAI Revista de Administração e Inovação, pp. 226-250.

Pinto, J. C., Mazieri, M. R., \& VILS, L. (2017). Análise léxica automatizada em administração de empresa. VI SINGEP.

Prahalad, C. K., \& Hart, S. L. (2002). The fortune at the bottom of the pyramid. Strategic Business, pp. 55-67.

Ratinaud, P. (2009). Iramuteq: Interface de R pour les Analyses Multidimensionnelles de Tex-tes et de Questionnaires [Computer software]. Retrieved from http://www.iramuteq.org. Computer software: Retrieved from http://www.iramuteq.org.

Raufflet, E. (2008). Creating the Context for Corporate Responsibility. Journal of Corporate Citizenship, 95-106.

Raufflet, E., \& Do-Amaral, C. G. (2007). Bridging business and society: the Abrinq Foundation in Brazil. Journal of Business Ethics, pp. 119-128.

Sampaio, M. A. (2015). $360^{\circ}$ : o périplo do açúcar em direção à Macrorregião Canavieira do Centro-Sul do Brasi. São Paulo: Tese (Doutorado em Geografia Humana) - Universidade de São Paulo.

Santos, G., Santos, A., \& Sehnem, S. (jan/jun de 2016). Como mensurar a sustentabilidade? Um estudo das principais técnicas e indicadores. Organizações $e$ Sustentabilidade, pp. 3-48.

Sartori, S., Latronico, F., \& Campos, L. (2014). Sustentabilidade e desenvolvimento sustentável: uma taxonomia no campo da literatura. Ambiente e Sociedade [online], pp. 1-22.

Schaltegger S., W. M. (may de 2011). Sustainable entrepreneurship and sustainability innovation: categories and interactions. Business Strategy and the Environment, pp. 222-237.

Schommer, P. C., \& Fischer, T. (maio/agosto de 1999). Cidadania empresarial no Brasil: os dilemas conceituais e a ação de três organizações baianas. Organizações \&Sociedade, pp. 99-118.

Schumpeter, J. A. (1985). Teoria do desenvolvimento econômico: uma investigação sobre lucros, capital, crédito, juro e o ciclo econômico. Nova Cultural.

Shikida, P. F., \& Souza, E. C. (julho/setembro de 2009). Agroindústria canavieira e crescimento econômico local. Revista de Economia e Sociologia Rural., pp. 569-600.

Shikida, P. F., Azevedo, P. F., \& Vian, C. E. (2011). Desafios da agroindústria canavieira no Brasil pós-desregulamentação: uma análise das capacidades tecnológicas. Revista de Economia e Sociologia Rural, pp. 599-628.

Silva, C. R., Gobbi, B. C., \& Simao, A. A. (2005). O uso da análise de conteúdo como uma ferramenta para a pesquisa qualitativa: Descrição e aplicação do método. Organizações Rurais Agroindustriais, 7(1), 70-81.

Silva, D. (2015). Oportunidades de Inovação no Setor Sucroenergético. Rio de Janeiro: Dissertação (Mestrado em Engenharia Química) - Universidade Federal do Rio de Janeiro - Escola de Química - Programa de Pós-Graduação em Tecnologia de Processos Químicos e Bioquímicos.

Siqueira, P. H. (2013). Estratégias de crescimento e de localização da agroindústria canavieira brasileira e suas externalidades. Lavras: Tese (Doutorado em Dinâmica e Gestão de Cadeias Produtivas) - Universidade Federal de Lavras.

Tenório, F. G. (2006). Responsabilidade Social Empresarial: Teoria e Prática.FGV.

Tinoco, J. E. (2001). Balanço Social: uma abordagem da transparência e da responsabilidade pública das organizações. Atlas.

União da Indústria de Cana-de-Açucar UNICA (2020). Setor sucroenergético - Mapa da Produção, 2019-2020. Fonte: UNICA (União da Indústria de Canade-Açúcar): <http://www.unica.com.br/mapa-da-produção/ .pdf

Tranin, M. R. (12 de 02 de 2020). Setor Sucroalcooleiro: o futuro é promissor. Fonte: Jornal Paraná: https://www.jornalparana.com.br/noticias UNICA. (2020). Setor sucroenergético - Mapa da Produção, 2019-2020. Fonte: UNICA (União da Indústria de Cana-de-Açúcar): <http://www.unica.com.br/mapa-da-produção/.pdf

Vasconcelos, A. C., Andrade, E. D., \& Cândido, G. A. (2009). Indicadores de sustentabilidade e suas influências no desenvolvimento local: uma aplicação em região produtora de mamona no Estado da Bahia. Revista de Gestão Social e Ambiental, pp. 105-120.

Vilella, J. N. (2015). Responsabilidade Social e Ambiental como nova competência da Gestão de RH. Fonte: IDEMP 2015: http://idemp-edu.com.br/artigos/36 
Research, Society and Development, v. 10, n. 4, e32610414317, 2021

(CC BY 4.0) | ISSN 2525-3409 | DOI: http://dx.doi.org/10.33448/rsd-v10i4.14317

Wissmann, M. A., Shikida, P. F., \& Ayala, J. C. (out/dez de 2018). Responsabilidade Social nas Agroindústrias Canavieiras no Brasil. Revista de Economia e Sociologia Rural, pp. 681-700.

Wissmann, M., \& Shikida, P. (julho de 2017). Impactos Econômicos, Ambientais e Sociais da Agroindústria Canavieira no Brasil. Revista Desenvolvimento, Fronteiras e Cidadania, pp. 134-160. 